\title{
Lipid profile in patients with alcohol dependence syndrome
}

\author{
Mithileshwer Raut, ${ }^{1 *}$ Prashant Regmi, ${ }^{2}$ Saroj Prasad Ojha, ${ }^{3}$ Bharat Jha ${ }^{1}$
}

\begin{abstract}
BACKGROUND: Alcohol dependence syndrome (ADS) has become a global public health challenge because of its high prevalence and the concomitant increase in risk of liver disease, cardiovascular disease and premature death. Influence of alcohol use on lipid metabolism is well recognized. Investigations had been carried out in the earlier period on abnormal lipid profile as a risk factor for Coronary Heart disease (CHD). Patients of alcohol dependence usually have a consumption pattern of more heavy use. Therefore it is useful to study the lipid profile in patients of alcohol dependence, to understand the effects of increasing levels of consumption.
\end{abstract}

METHODS: This cross-sectional study was conducted in TU Teaching Hospital. ADS patients were screened by the consultant psychiatrist using the Alcohol Use Disorder Identification Test (AUDIT) questionnaire. A total of 89 patients scored positive on the AUDIT as having alcohol-related problems and were included in the study. 89 ADS patients and 89 healthy controls both male and female were enrolled as participants. Blood Pressure and other anthropometric parameters were measured while fasting blood samples were analyzed for serum lipid profile. SPSS program was used to analyze data, $t$-test $\&$ Spearman's correlation coefficient was used to find correlation.

RESULTS: Among the ADS cases 95\% were current smokers. Mean age of cases and controls was $35.42 \pm 5.6 \& 34.53 \pm 3.5$ years respectively. The mean total cholesterol levels were found to be higher in cases $(5.41 \pm 0.70)$ than controls $(3.79 \pm 0.74)$ with a strong statistical significance $(\mathrm{p}<0.001)$. Also, Mean triglyceride (TG) levels $(2.09 \pm 0.72)$, along with the mean HDL-cholesterol $(1.66 \pm 0.40)$ and LDLcholesterol levels $(2.79 \pm 0.81)$ were also elevated in cases when compared to the control samples $(\mathrm{p}<0.001)$.

CONCLUSION: This study has demonstrated definitive lipid profile changes in patients of alcohol dependence, with some correlation to the liver dysfunction. Alcohol causes alteration in various parameters of lipid metabolism including those which predispose to CHD. Low to moderate alcohol use over prolonged periods has been linked to have protective influence for development of coronary heart disease (CHD), through increase in high density lipoprotein cholesterol (HDL-C) levels.
Key words: ADS (Alcohol dependence syndrome), CHD (Coronary heart disease), HDL-C (high density lipoprotein cholesterol), TG (Triglyceride), LDL-C (Low density lipoprotein cholesterol)

(C) 2015 Nepalese Association for Clinical Chemistry

\section{Introduction}

Alcohol consumption might be the cause of several diseases, and it is, well known, the high burden of its consumption over mortality around the world [1]. Alcohol is the only psychoactive drug that provides energy $(7.1 \mathrm{kcal} / \mathrm{g})$. However, its calories are considered "empty," because alcohol ingestion does not provide vitamins and minerals [2] and its use may cause alterations to the nutritional state [3]. Alcohol dependence syndrome is defined as "A cluster of physiological, behavioral, and cognitive phenomena in which the use of a substance or a class of substances takes on a much higher priority for a given individual than other behaviors that once had greater value [4]. Hazardous alcohol intake and related disorders are a major health issue. A World Health Organization (WHO) project on psychological problems in general practice has shown that alcohol dependence or harmful alcohol use is present in about $6 \%$ of patients attending primary care, ranking third in frequency after major depression and generalized anxiety [5]. Harmful or heavy alcohol drinking makes a substantial contribution to the burden of disease and premature mortality [6]. Among persons admitted to general hospitals, 20 to 40 percent have alcohol-related problems, and among the elderly, alcohol-related hospitalizations are as numerous as those due to myocardial infarction [7]. The liver is the organ most severely affected by alcoholism. In some urban areas, cirrhosis (usually a complication of alcoholism) is the fourth most frequent cause of death among people 25 to 64 years of age [8]. Different studies have been done in alcoholic liver diseases but only few studies have been done in alcohol dependence syndrome. Alcohol abuse is a major 
health problem as well as social problem in the community. Patients of alcohol dependence usually have a consumption pattern of more heavy use. Therefore it is useful to study the lipid profile in patients of alcohol dependence, to understand the effects of increasing levels of consumption. Alcoholism may lead to the different health consequences, like alcoholic liver diseases, cardiovascular diseases, and kidney diseases. So, the early diagnosis of ADS can help the patient to prevent from these major health problems.

\section{Methods}

This cross-sectional study was conducted in TU Teaching Hospital. ADS patients were screened by the consultant psychiatrist using the Alcohol Use Disorder Identification Test (AUDIT) questionnaire. The aim of the study and the questions in the questionnaire form were fully explained to the patients. A total of 89 patients scored positive on the AUDIT as having alcoholrelated problems and were included in the study. 89 ADS patients and 89 healthy controls both male and female were enrolled as participants. Blood Pressure and other anthropometric parameters were measured while fasting blood samples were analyzed for serum lipid profile. Serum is used for analysis of lipid profile and traditional marker of alcoholism. Total cholesterol was estimated by enzymatic method as described by Allain et al [9]. Serum triglyceride was estimated by Fossati and Prencipe method [10] associated with Trinder reaction [11]. HDLCholesterol was estimated by precipitation method, in which chylomichron, LDLcholesterol and VLDL were precipited and the supernatant fluid containing HDL-cholesterol were estimated by cholesterol method. LDLcholesterol was calculated using the Friedewald formula [12]. Serum glutamate pyruvate transferase (SGPT), Serum glutamate oxaloacetate transferase (SGOT) and gamma glutamyl transferase (GGT) were estimated by enzymatic method. The test was performed by reagent manufactured by Human, Germany, in the fully automated chemistry analyzer, BT 3000 , Italy.

Laboratory standard operation procedures were maintained for all laboratory analysis. Internal quality control sera, both normal and pathological, were also run for each lot of the test, for the validation of the results. SPSS program was used to analyze data, t-test
\&Spearman's correlation coefficient was used to find correlation.

\section{Results}

Mean age of the patients and control subjects was $35.42 \pm 5.6$ years and $34.53 \pm 3.5$ years respectively. Range of age was $25-47$ years for both groups. The majority of subjects (78\%) had begun voluntarily, while $22 \%$ claimed to have done so due to peer pressure. The average daily intake of alcohol as stated by the patients was $71.36 \mathrm{gm}$. The mean duration of drinking was 12.0 years (Range 5-28 years). The frequency of consumption was: daily in $48 \%$ patients, $3-5$ times a week in $41 \%$ patients. The majority of alcohol dependent patients (72\%) consumed alcohol alone while $28 \%$ claimed to drink only in company.

Table 1. Comparison of mean age of ADS cases and healthy control

\begin{tabular}{lcc}
\hline Subject class & Mean \pm SD & p-value \\
\hline Cases & $35.42 \pm 5.6$ & 0.201 \\
Controls & $34.53 \pm 3.5$ & \\
\hline Applied one way ANOVA test, statistically significant at p-
\end{tabular}

Applied one way ANOVA test, statistically significant at pvalue $<0.05$

Table 2. Comparison of mean of Lipid profile between cases and controls

\begin{tabular}{lccc}
\hline & $\begin{array}{c}\text { Control } \\
\text { Mean } \pm \text { SD }\end{array}$ & $\begin{array}{c}\text { Case } \\
\text { Mean } \pm \text { SD }\end{array}$ & $\begin{array}{c}\text { p- } \\
\text { value }\end{array}$ \\
\hline Total & $3.79 \pm 0.74$ & $5.41 \pm 0.70$ & 0.001 \\
Cholesterol & & & \\
Triglyceride & $1.23 \pm 0.60$ & $2.09 \pm 0.72$ & 0.001 \\
HDL-C & $1.08 \pm 0.24$ & $1.66 \pm 0.40$ & 0.001 \\
LDL-C & $2.15 \pm 0.90$ & $2.79 \pm 0.81$ & 0.001 \\
\hline
\end{tabular}

Applied one way anova test, statistically significant at pvalue $<0.05$

Table 3. Comparison of mean of different traditional marker and liver enzymes between ADS patients and normal healthy control

\begin{tabular}{lccc}
\hline & $\begin{array}{c}\text { Control } \\
\text { Mean } \pm \text { SD }\end{array}$ & $\begin{array}{c}\text { Case } \\
\text { Mean } \pm \text { SD }\end{array}$ & $\begin{array}{c}\text { p- } \\
\text { value }\end{array}$ \\
\hline Gamma-GT & $41.80 \pm 10.56$ & $181.02 \pm 78.16$ & 0.001 \\
MCV & $89.77 \pm 2.18$ & $97.22 \pm 4.6$ & 0.001 \\
SGOT & $35.26 \pm 14.27$ & $114.35 \pm 46.22$ & 0.001 \\
SGPT & $26.30 \pm 10.6$ & $60.28 \pm 13.12$ & 0.001 \\
\hline
\end{tabular}

Applied one way anova test, statistically significant at pvalue $<0.05$ 
Table 4. Spearman's correlation coefficient of GGT with Lipid profile between cases

\begin{tabular}{lcc}
\hline & $\begin{array}{c}\text { Spearman's } \\
\text { rho }\end{array}$ & p-Values \\
\hline Total Cholesterol & 0.081 & 0.449 \\
Triglyceride & -0.005 & 0.964 \\
HDL-C & -0.067 & 0.528 \\
LDL-C & 0.105 & 0.323 \\
\hline
\end{tabular}

The table 4 shows the Spearman's correlation of GGT with lipid profile between the cases and controls. GGT was not significantly correlated with lipid profile.

Table 5. Spearman's correlation coefficient of SGOT with Lipid profile between cases

\begin{tabular}{lcc}
\hline & $\begin{array}{c}\text { Spearman's } \\
\text { rho }\end{array}$ & p-Values \\
\hline Total Cholesterol & 0.037 & 0.730 \\
Triglyceride & -0.128 & 0.228 \\
HDL- & 0.128 & 0.231 \\
Cholesterol & & \\
LDL-cholesterol & 0.020 & 0.849 \\
\hline
\end{tabular}

The table 5 shows the Spearman's correlation of SGOT with lipid profile between the cases and controls. SGOT was not significantly correlated with lipid profile.

Table 6. Spearman's correlation coefficient of MCV with Lipid profile between cases

\begin{tabular}{lcc}
\hline & $\begin{array}{c}\text { Spearman's } \\
\text { rho }\end{array}$ & p-Values \\
\hline Total Cholesterol & 0.065 & 0.542 \\
Triglyceride & 0.004 & 0.969 \\
HDL- & 0.089 & 0.407 \\
Cholesterol & & \\
LDL-cholesterol & 0.027 & 0.804 \\
\hline
\end{tabular}

The table 6 shows the Spearman's correlation of MCV with lipid profile between the cases and controls. MCV was not significantly correlated with lipid profile.

\section{Discussion}

The mean total cholesterol levels were found to be higher in cases than controls with a strong statistical significance. Mean TG levels, along with the mean HDL-cholesterol and LDLcholesterol levels were also elevated in cases when compared to the control samples. Within the group analysis of cases, it revealed borderline high total cholesterol in about half of the cases and very high level of total cholesterol was seen in one-tenth of the patients.

Also, among the cases, majority had elevated triglycerides level. LDL cholesterol was normal in most of the patients. A elevated HDL cholesterol was noted in more than half of the cases. These features are in the line of the notion of cardio protective effect of alcohol consumption by maintaining the level of LDL and HDL with an expense of slightly raised triglyceride level. The present study needs to be seen in the light of earlier studies which appear to confirm the linear relationship between increasing amounts of alcohol use and lipid profile changes known to have protective role for CHD [13]. Alcohol consumption has been found to be associated with increased serum levels of $\mathrm{Tg}$ and high density lipoproteins (HDL) $[14,15]$. The increase in HDL cholesterol has been estimated to account for half of the beneficial effects of alcohol consumption on cardiovascular events. 16 Alcohol has narrow therapeutic range and only the moderate drinking has beneficial effects on cardiovascular health [17]. Prolonged excessive drinking causes various structural and functional abnormalities of heart.

\section{Conclusion}

In conclusion, this study has demonstrated definitive lipid profile changes in patients of alcohol dependence, with some correlation to the liver dysfunction. Alcohol causes alteration in various parameters of lipid metabolism including those which predispose to CHD. Low to moderate alcohol use over prolonged periods has been linked to have protective influence for development of coronary heart disease (CHD), through increase in high density lipoprotein cholesterol (HDL-C) levels. 


\section{REFERENCES}

1. World Health Organization .(WHO). Global status report on alcohol and health. 2011; Available at: http://www.who.int/ substance_abuse/publications/global _alcohol_report/msbgsruprofiles.pdf. Acessed May 2012.

2. Molina PE, Hoek JB, Nelson S, Guidot DM, Lang CH, Wands JR, Crawford JM. Mechanisms of alıcohol induced tissue injury. Alcohol Clin Exp Res. 2003;27(3):563-575.

3. Lieber CS. Medical disorders of alcoholism. N Engl J Med. 1995;333(16):1058-1065.

4. World Health Organization (1992) International Classification of Diseases and Related Health Problems, 10th edn. World Health Organization, Geneva.

5. Goldberg D, Lecrubier Y. Forms and frequency of mental disorders across centers. In: Ustun TB, Sartorius N, eds. Mental illness in general health care: an international study. New York, John Wiley, 1995:324-34.

6. Balabanovaa D, McKee M. Pattern of alcohol consumption in Bulgaria.
Alcohol and alcoholism, 1999, 34:622-8.

7. Adams WL, Yuan Z, Barboriak JJ, Rimm AA. Alcohol-related hospitalizations of elderly people. JAMA 1993; 270:1222-5. [Erratum, JAMA 1993; 270:2055.

8. Bureau of Health Statistics and Analysis. Summary of vital statistics, New York. New York: Department of Health, City of New York, 1986.

9. Allain, CC, Poon LS, Chan CS. Enzymatic determination of total serum cholesterol, Clin. Chem 1974; 20:470-475.

10. Fossati P, Prencipe L. Serum triglycerides determined colorimetrically with an enzyme that produces hydrogen peroxide. ClinChem 1982; 28: 2077-2080.

11. Trinder P. Determination of glucose in blood using glucose oxidase with an anternative oxygen acceptor. Ann Clin Biochem 1969; 6:24-7.

12. Friedewald. 1972. Friedewald WT, Levy RI, Fredrickson DS: Estimation of the concentration of low-density lipoprotein cholesterol in plasma without use of the preparative ultracentrifuge. Clin Chem 1972; 18:499-502.

13. Taskinen, M.R.; Nikkila, E.A.; Valimaki, M.; Sane, T.; Kunsi, T.;Kesanteoni, Y.A \&Ylikhari, R. (1987) Alcohol induced changes in serum lipoproteins and their metabolism. American Heart Journal, 113,458-464.

14. J.J. Frohlich. Effects of alcohol on plasma lipoproteins metabolism. ClinChimActa 1996;246:39-49.

15. M.J. Savolainen, Y.A. Kesaniemi. Effects of alcohol on lipoproteins in relation to coronary heart disease. CurrOpinLipidol 1995;6:243-50.

16. M.H. Criqui, L.D. Cowan, H.A. Tyroler, et al. Lipoproteins as mediators for effects of alcohol consumption and cigarette smoking on cardiovascular mortality: results from the Lipid Research Clinics Follow-up Study. Am J Epidemiol 1987;126:629-37.

17. S.A. Schuckit. Alcohol and Alcoholism. In: E. Braunwald, A.S. Fauci, D.L. Kasper, et al. editors. Harrison's Principle of Internal Medicine. 15th edition, New York: Mc-Graw Hill; 2001. 2561-6. 